\title{
Layered Documentation-On the Process of Documenting Contemporary Dance and Physical Theatre
}

\author{
Maria Mercè Saumell Vergés \\ Institut del Teatre, Barcelona, Spain
}

\begin{abstract}
How can choreography and physical theatre pieces continue to perpetuate the work after rendering? How to preserve their aura, their dynamics, and their ephemeral and genuine nature, as Walter Benjamin said? In 1936, Benjamin already anticipated in The Work of Art in the Age of Its Technological Reproducibility that something is missing even in the best-finished reproduction. And memories of dance and physical theatre are intricate. The question is how to create a type of documentation that does not betray the vital flow of the event-based phenomenon. In this short article we will see a series of choreographic and performance artists like Esther Ferrer, Ayara Hernández Holz, and Olga de Soto who claimed a new form of organic documentation, making it turn performance or memory of viewers. Other creators as the company La Fura dels Baus claim documentation as spectacle and others on the opposite side, as Tino Sehgal propose radically non documentation of their work. Precisely, these different positions coincide with those of thinkers like Peggy Phelan, Sarah Bay-Cheng, or Paula Caspão who respect to a range of documentation and how it can never replace the live art.
\end{abstract}

Keywords: documentation methodologies, digital archives, processes of creation, re-readings, (non)documentation

\section{Introduction}

At present, under the current regime of technological reproducibility, images can survive through time, however corporeal effects created by performance cannot. This contrast has created a fascinating theoretical debate and, at the same time, a transformation regarding the concept of documentation itself, presently much more closely associated with the creative process and the new digital platforms.

\section{Ontologies}

Recently, further methods of theorizing ephemerality shifted towards the idea of performance as disappearance.

We especially note the contribution of Phelan with her famous book Unmarked: The Politics of Performance (1993), and also the contribution of Schneider who develops that subject in her book Performing Remains: Art and War in Times of Theatrical Reenactment (2011). However, the existence of digital archives introduces the notion of ephemerality from other perspectives, questioning the very limits of the performance act by way of the immediate access to various simultaneous sources of information (about the show itself, about its creators, and about the place where the stage action was carried out, the making-of, interviews, images of the show with various casts, reenactments, and so on).

Maria Mercè Saumell Vergés, Ph.D., professor, Institut del Teatre. 
Bay-Cheng in her paper "Theatre is Media. Some Principles for a Digital Historiography of Performance" (2012) posits that theatre, dance, and performance history actually cannot be understood independently of digitized forms of media that "perform" documentation. The idea that media acts as an intrinsic part of performance history calls attention to the interdependent relationship between the act of archiving material and the actual process of generating and creating that material. Because recent documentation and digital technologies have complicated traditional archiving procedures by altering the processes by which we locate the available documents, how we reconstruct the event and the nature of the documents themselves.

In this sense, on materials and accumulated memories, settled in different layers and overlapping records, Bay-Cheng proposes,

Performance for more than one hundred and fifty years has responded to the effects of recording, first in photography, then cinema, and now digital recording and circulation. Our historiographic methods should account for the digital as performance as much we recognize that the performance event mediates. (Bay-Cheng, 2012, p. 37)

If we focus on the documentation of dance, in spite of the diverse systems and attempts of notation throughout the history of dance, bodies in movement escape from their own materiality and are essentially transformed into memory, a place where the logic of priorities is subjective. As we shall see, subjective memory is working its way into the new documentation methodologies, less rigid in regards to "scientific" criteria and more open to concepts that are more difficult to measure, such as emotion or the creative process itself.

But let's return to the ephemeral character of performance arts. As was pointed out at the beginning, Phelan thinks: "Performance's life is only in the present. Performance cannot be saved, recorded, documented, or otherwise participate in the circulation of representations of representations: once it does so it becomes something other than performance" (Phelan, 1993, p. 51). However, technology has advanced nonstop since her book from 1993 and these innovations have also modified the theoretical discourses on live arts documentation.

During the same time period, in the 90 s, on an international level there was a true "documentation fever" in the field of dance precisely to prevent the disappearance and the corresponding oblivion following the performance. The question is: How to produce a type of documentation that does not betray the event? We can discuss the example of the Re.act.Feminism 2-A Performing Archive travelling through six European countries from 2011 to 2013 where we can find works over 180 female artists and female artists collectives from the 1960s to the beginning of the 1980s. Indeed, the first country was Spain and continuing through Poland, Croatia, Denmark, Estonia, and ending in Germany. The promoters of this interesting initiative, Bettina Knaupp and Beatrice Stammer, began investigating the veteran Basque performer Ester Ferrer who wrote in 1998: "To reenact a performance with documentation is like preserving the stage actions as if they were a taxidermic trophy" (Ferrer, 2011, p. 43).

It is interesting that in Spanish, Ferrer explicitly uses the verb related to the practice of taxidermy, which is defined as the art or process of preparing, stuffing, and mounting animal skins so that they have a lifelike appearance, facilitating their exhibition, study, and preservation. That is, the idea of lifeless bodies.

In this regard, it seems pertinent for me to quote - in the opposing sense - the opinion of the Portuguese researcher, Paula Caspão, who lives in Barcelona. She points out that documentation seen as a relic is not synonymous with dead material, as long as the relic continues to live on in the memory:

Our archives are full of corpses and we should better acknowledge that what we have experienced once in a lifetime is 
not anymore and will never again be exactly the same way. That, in a way, is life, and performance performing life. Only, it is not that simple. Corpses or any other stiff bodies are seldom that dead. (Caspão, 2007, p. 145)

For her, documentation is as organic as creation.

\section{Processes of Creation}

Maybe we could point to a potentially new paradigm in dance and physical theatre documentation similar to the artist's original process of creation: documents, interviews as a useful tool, exhibition documentation, and environmental parameters.

We consider that performance is a process and the public presentation is only the end result of several months of rehearsals, repetitions, and re-interpretations. Dance companies or physical theatre companies might create hundreds of hours of video footage of rehearsals and these records can be used in multiple contexts for both performers and researchers. However archives are often focused only on the end result. In order to reconstruct the artistry of dance or physical theatre production, records such as costumes, playbills, maquettes, viewing rehearsals, and talks with the creators, are also extremely important.

Documentation on the processes of creation portrays the archive as a presentation of art "in-the-making".

\section{Digital Archives}

Digital archives relating to the performance arts should reflect their complexity and accommodate hybrid media as well as all the networking possibilities. As mentioned before, digital recording and storing processes now influence our notion of dance and physical theatre history. Archives are more dispersed and also democratic, accessible from anywhere, as opposed to a single archive location. Digital media present an innovative turn in archiving strategies that capture motion "in process".

Visual recordings provide an expanding medium through performance and rehearsal which can be preserved in such a way as to demonstrate multiple viewing perspectives and the presence of live bodies. The transition to digitization exposes an expansion to the idea of the archive and its relationship to the preservation of the contemporary performance arts history. As such, the impulse to catalogue information on the Internet not only reiterates the aim of rendering performance arts history accessible to the public, but also reveals the utility of digital media in doing so. Now it is about digital media that store text, image, and sound.

We can consider that both documentation and performance in this context require careful attention not only to the multiple parts of the performance as such but also to the ways in which the performance, documentation, and reception are mediated through smartphones, websites, images, and social media exchanges including e-mails, video streaming and so on. All this takes part in the performance as well as its history.

With regard to this overexposure to information, the nostalgic attitude of certain creators should come as no surprise, as will be pointed out towards the end of this paper, underlining the need to live and defend the moment of the performance as a unique experience.

On other occasions, different audiovisual sources can be added to a composition produced with prerecorded images and sounds. Likewise, images captured live can be modified or computer graphics can be used. All these phenomena are made possible by the idea we call "real-time", a term that has essentially emerged with the advent of digital media. We see this in shows such as those by the British company Blast Theory, The Wooster Group from New York, or La Fura dels Baus from Catalonia, among many other formations. 


\section{The Archive of La Fura dels Baus}

Very recently, the Documentation Center and Museum of Performing Arts of the Institut del Teatre de Barcelona (see from www.cdmae.cat) has welcomed the entire historical archive of La Fura dels Baus. The archive of this company, founded in 1979, is of enormous interest to researchers, as it gathers the creation processes of all its shows since the outset, from its beginnings in street theatre to physical theatre performance, the opening ceremony of the 1992 Barcelona Olympic Games to their current opera productions.

This archive contains 2349 records (which include over 5,000 photographs, large numbers of posters, articles, and journalistic criticism, audiovisual recordings, drawings, budgets, and various materials on the process of creation...) corresponding to 172 productions of different types and theatrical formats.

Also this is an archive that will allow us to explore different methodologies and supports (from the initial story-boards drawn on paper to the most recent and sophisticated projects with 3D models and computer graphics). This wealth of languages is reflected in the documentation of their archive through combined sketches, previous interviews, photographs, and videos of the production processes and rehearsals.

On another level, this archive also shows us the speed at which technological changes have occurred in the field of audiovisual documental recording of the performance arts over the past 30 years. We find many recordings made on early Beta, VHS, DVD, and DvCpro tapes from the 80 s that need to be transferred to a digital format in order to be preserved and shared. We have also found that the majority of the physical materials belong to the first decades of the company and how in later years the digital support has "immaterialized" the documentation.

It should be noted that the theatre company has always had an interest in documentation. Here we would underscore their proposal of documenting their creation processes, even incorporating them into commercial products such as the DVDs of their operatic performances, a genre that is sufficiently financed so as to publish high quality recordings with additional documentary materials.

For example, the opera Le Grand Macabre, by György Ligeti, staged in 2009 by Àlex Ollé. The DVD produced by the German company Arthaus Musik released in 2012 also contains quality documental extras. This operatic co-production between the Théâtre Royal de la Monnaie in Brussels and the Grand Teatre del Liceu in Barcelona required a complex production process that is wonderfully reflected in the extras featured in this audiovisual product. Fear to Death, a highly elaborate Making Of is designed more as a stand-alone product than a mere DVD extra. This 34-minute long audiovisual material, produced by Xavi Bové, gathers together interviews, original materials such as sketches and models, as well as images from rehearsals in La Monnaie.

The result of this special feature is a valuable insight into the entire creation process of the opera that, in this case, revolves around an initial image of a grotesque and gigantic body-Claudia - that gets its inspiration from the hyperrealist sculptures by Ron Mueck. The action of the opera, based on the 1934 play by the Flemish playwright Michel de Ghelderode, takes place inside the body of the giant doll- the colossal alter ego of the opera singer Claudia Schneider. The bizarre characters of this satirical opera inhabit the body. The characteristics of the 3D projections onto Claudia's skin, the complexity of the construction of such a gigantic body, and the interaction with singers and actors provide extensive knowledge and documentation regarding the genesis and production of this magnificent mise-en-scène. 


\section{Documentation as Performance}

More recently, we should mention a series of performances constructed around re-readings of the documentation of performances or the testimonies of spectators as they recall the experience 20,30, or even 60 years later. In these examples we do not speak of performance reenactments, as would be the case of the internationally renowned performer Marina Abramović regarding her own past performances.

Let's consider the example of the Spanish choreographer Olga de Soto. Starting from a documentary process, she created the performance Histoire(s) in 2004. Olga de Soto not only transformed a documentation process into a performance, she also transformed the very act of performing into one of documentation, displacing both notions of documentation and dance performance.

She chose to pay tribute to the ballet The Young Man and Death (1946) choreographed by Roland Petit based on a libretto by Jean Cocteau. The première, shortly after Second World War, was at the Théâtre des Champs Elysées in Paris. Instead of reconstructing the ballet itself, Soto followed the thread of the witnesses' memories of its première. The result doesn't help us to follow the ballet in question. We see a choreographic recomposition of several moments, spaces, and memories constructed around a documentary film. Projected on four screens of different sizes, the film shows people in their homes talking about their memories of the ballet 58 years later at a very significant historical period: life after the war. The portraits of people speaking constantly change, as they visibly change in their mental and affective memories.

\section{Unofficial Documentation}

Returning to the subject of "documentation fever" that both institutions and creators have suffered recently, there are other disparate voices regarding unofficial documentation.

Consider the case of the Uruguayan choreographer Ayara Hernández Holz, now Berlin-based. She is only concerned with the traces that remain in the memory of viewers. However, just like a family photo, these memories evoke much more than the image itself: the memory that surrounds that photographic instant, inviting us to evoke its "aura" (according to Walter Benjamin's concept).

She defines it as "organic documentation" (Hernández Holz, 2010). Nothing is set or fixed in this kind of documentation because by respecting the natural memory process, the "documentation" is continuously transformed into a never-ending game of translations and transpositions. The interesting thing is that she does not want to stage or preserve any record of these memories. In contrast to Olga de Soto's project, she wants the memory of the performance to dissolve with the passage of time in the minds of her spectators, in the same way that time consumes their bodies.

Let's consider now the example of the renowned international artist Tino Sehgal who has created a strong discourse on the (non)documentation of his works. As in the case of Hernández Holz, this statement has also resulted in the dissemination of his work basically by word of mouth.

Sehgal is a London born conceptual artist who has made his name by creating "constructed situations". No material evidence of Sehgal's work officially exists. He worked with the experimental choreographers Jérôme Bel and Xavier Le Roy and his refusal to allow documentation should not, however, be read as a rejection of new technologies but rather as more of an ethical and political decision. He wants to favor the transitory live exchange between audience and interpreters.

Dance and economy interact in his work, suggesting an interrelation between today's economics models 
and the situations generated by live bodies. (Non)documentation has become his "label" of resistance against the production of tangible objects. This proposal seems attractive to us because it goes against an economic system based on excess, but in spite of this discourse, we cannot deny that he forms part of the contemporary art market and, for example, Sehgal consented to give several interviews on the occasion of winning the Golden Lion at the 2013 Venice Biennale. Maybe because, in short, in our consumer society, (non)documentation is equivalent to being forgotten.

\section{Conclusion}

We have sought to gather and defend a series of concerns regarding the documentation of today's performance arts, with special focus on dance and physical theatre. We have quoted several theoretical arguments and also the emergence of new archival supports, interests and methodologies. Additionally we have highlighted how archives specialized in the performing arts are placing an ever-increasing importance on everything related to the creation process, study, and documentation, viewing these as an intrinsic part of live arts.

\section{References}

Bay-Cheng, S. (2012). Theatre is media. Some principles for a digital historiography of performance. Theatre, 42 (2), $26-41$.

Benjamin, W. (2008). The work of art in the age of its technological reproducibility. Westminster: Penguin Books Ltd..

Caspão, P. (2007). Stroboscopic stutter on the not-yet-captured ontological condition of limit-attractions. The Drama Review, 51 (2), 136-156.

Ferrer, E. (1998). Ester Ferrer: De la acción al objeto (Since the action to the object). Sevilla: Centro Andaluz de Arte Contemporáneo.

Hernández Holz, A. (2010). La poética de la Desaparición (The poetics of Disappearance) (Master thesis Universitat de Girona).

Knaupp, B., \& Beatrice, S. (2011). Re.act. feminism 2-A performing Archive. Retrieved from http://www.reactfeminism.org/archive.php?l=lb

Phelan, P. (1993). Unmarked: The politics of performance. London: Routledge.

Schneider, R. (2011). Performing remains: Art and war in times of theatrical reenactment. London: Routledge. 